\title{
Effects of Acetazolamide, Paracetamol, and Placebo on Postoperative Pain in Laparoscopic Cholecystectomy: A Randomized, Double-blind, Parallel-controlled Clinical Trial
}

Arash Peivandi Yazdi ${ }^{1}$, Mehdi Asadi ${ }^{2}$, Mehryar Taghavi Gilani ${ }^{1}$, Alireza Bameshki ${ }^{3}$, Mostafa Mehrabi Bahar ${ }^{4}$, Mehdi Jabbari Noghabi ${ }^{5}$, Mahsa Rajaei ${ }^{6}$

${ }^{1} \mathrm{MD}$, Associate Professor of Anesthesia, Lung Disease Research Center, Faculty of Medicine Mashhad University of Medicine Sciences, Mashhad, Iran

${ }^{2} \mathrm{MD}$, Associate Professor of Surgery, Lung Disease Research Center, Faculty of Medicine Mashhad University of Medicine Sciences, Mashhad, Iran

${ }^{3}$ MD, Associate Professor of Anesthesia, Faculty of Medicine, Mashhad University of Medicine Sciences, Mashhad, Iran

${ }^{4} \mathrm{MD}$, Professor of Surgery, Mashhad University of Medical Sciences, Mashhad, Iran

${ }^{5} \mathrm{PhD}$, Associate Professor of Methodology, Epidemiologist, Faculty of Statistics, Ferdowsi University, Mashhad, Iran

${ }^{6} \mathrm{MD}$, Anesthesiologist, Department of Anesthesia, Mashhad University of Medical Sciences, Mashhad, Iran

Type of article: Original

\begin{abstract}
Introduction: In laparoscopic surgery, insufflation of $\mathrm{CO} 2$ gas into the peritoneal cavity creates referred postoperative pain and diffuse abdominal pain. Referred pain is sometimes more intensive than incisional and abdominal pain.

Objective: To determine the efficacy of acetazolamide by increasing $\mathrm{pH}$ and reducing acidity in the abdomen and to compare the analgesic effects of paracetamol and acetazolamide with a control group in laparoscopic surgery.

Methods: This randomized, double-blind, parallel-controlled clinical trial was conducted on ASA1 (American Society of Anesthesiologists Class 1) patients, who were candidates for laparoscopic cholecystectomy in teaching hospitals affiliated with Mashhad University of Medical Sciences during 2016-2017. One hundred fourteen patients were allocated equally into two study groups and one control group (receiving acetazolamide, paracetamol, or placebo). In the acetazolamide group, $250 \mathrm{mg}$ acetazolamide was administered one hour before anesthesia. In the paracetamol group, $1 \mathrm{~g}$ paracetamol was infused over a 15-min postanesthesia induction. Incision site, diffuse abdominal, and shoulder pains were evaluated at the recovery room the day after surgery and upon hospital discharge using a numeric rating scale (NRS). Data were analyzed by SPSS 16.0, using Chi-square for trend test, Fisher's exact test, paired-samples t-test, Wilcoxon signed-rank test, two-way repeated measure analysis of variance (ANOVA), and Mann-Whitney U test.

Results: There were no significant differences between groups regarding their demographic characteristics. The acetazolamide group exhibited a lower frequency of shoulder pain than the paracetamol and control groups at recovery $(\mathrm{p}=0.03), 24$ hours later $(\mathrm{p}=0.001)$, and before discharge $(\mathrm{p}=0.014)$. Incisional and diffuse abdominal pains were lower in the paracetamol group $(\mathrm{p}=0.012)$.

Conclusion: In the patients undergoing laparoscopic cholecystectomy, acetazolamide was effective in the reduction of shoulder pain and paracetamol was effective in postoperative incisional and abdominal pain control.

Registration: This study was registered In the Iranian Registry of Clinical Trials under registration number IRCT201206108384N2.

Funding: Research Vice-chancellor, Mashhad University of Medical Sciences (Ref: 900337).

Keywords: Acetazolamide, Paracetamol, Laparoscopic surgery, Referred pain
\end{abstract}

\section{Corresponding author:}

Associate Professor Dr. Mehryar Taghavi Gilani, Lung Disease Research Center, Faculty of Medicine Mashhad University of Medicine Sciences (Imam-Reza Hospital, Bahar Street), Mashhad, Iran.

Tel: +98.9155147696, E-mail: taghavim@mums.ac.ir

Received: January 22, 2019, Accepted: January 04, 2021, Published: March 2021

This article has been reviewed / commented by four experts

Ethics approval: Ethics committee of Mashahd University of Medical Sciences (Ref: IR.MUMS.REC.1390.14)

(C) 2021 The Authors. This is an open access article under the terms of the Creative Commons Attribution-NonCommercialNoDerivs License, which permits use and distribution in any medium, provided the original work is properly cited, the use is non-commercial and no modifications or adaptations are made. 
Abbreviations / Acronyms:

ASA: American Society of Anesthesiologists Class; CA: Carbonic Aanhydrase; NRS: Numeric Rating Scale

\section{Introduction}

Incisional pain site is perhaps the most common reason for a prolonged hospital stay. Therefore less invasive procedures, such as laparoscopy, are becoming popular nowadays (1). Carbon dioxide gas is non-combustible, quickly dissolves in the bloodstream, and is readily absorbed in the respiratory device for excretion (2). Therefore, carbon dioxide is used more commonly given its lower complication rate than helium, air, and nitric oxide. In the abdominal cavity, carbon dioxide reacts with water to form proton and bicarbonate. The two produced ions irritate the intra-abdominal tissues of the incision site, internal organs, and diaphragm causing incisional and referred pain (such as shoulder pain) (3). In recent years, numerous studies have been conducted to reduce the patients' postoperative pain and length of hospital stay, recommending methods such as small-port procedures, intraperitoneal analgesic injection, and pneumoperitoneum pressure reduction (4). Another method to control pain is the use of nonsteroidal anti-inflammatory drugs (NSAIDs) and paracetamol, which are effective in pain relief for incisional and non-incisional pains especially when administered prior to the pain onset. Several alternative techniques, such as the use of warm/humidified carbon dioxide or the administration of alfentanil prior to the insufflation, have been proposed in this regard (4). Paracetamol exerts its analgesic effect by inhibiting the production of prostaglandins through cyclooxygenase (5). The acetazolamide, a carbonic anhydrase (CA) inhibitor, initiates 1-1.5 hours after oral administration and lasts for 8-12 hours. Referred pain after laparoscopic surgery can be reduced by inhibiting this enzyme and reducing the produced $\mathrm{H}+$ ions $(5,6)$. The reduction of extracellular $\mathrm{pH}$ can cause the acid-sensitive ion and transient receptor potential channels to open, leading to muscular or visceral pain $(7,8)$. One of the most important biochemical reactions in proton production while resting is the reversible hydration of carbon dioxide, which is catalyzed by CA (9). Therefore, CA plays an important role in the regulation of extracellular PH. Furthermore, CA enhances the production of protons from carbon dioxide, which can increase the activity of the muscle fibers (10). With this background in mind, the present study aimed to compare the analgesic effects of paracetamol and acetazolamide in laparoscopic procedures.

\section{Material and Methods}

\subsection{Research design}

This Randomized, double-blind, parallel-controlled clinical trial was conducted on 114 ASA1 (American Society of Anesthesiologists Class I) patients undergoing laparoscopic cholecystectomy surgery, who referred to Imam-Reza Hospital of Mashhad University of Medical Sciences from January 2015 to January 2016 (one year). The patients were randomly allocated into three groups of acetazolamide, paracetamol, and placebo through a random number table and closed envelopes. Following Phelps et al. (12), with a prevalence of shoulder pain about $63 \%$ and a decrease of about $30 \%$, and a sampling error of $5 \%$ and a power of $80 \%$ in each group of 38 patients (total of 114 patients in three groups) were considered for the calculations using the statistical software NCSS/PASS.

\subsection{Selection criteria}

2.2.1. Inclusion criteria

ASA1 patients undergoing laparoscopic cholecystectomy surgery.

\subsubsection{Exclusion criteria}

The exclusion criteria were: 1) opioid drug dependency, 2) consumption of any kinds of analgesics 48 hours before the surgery, 3) diclofenac allergy, 4) any pain sensation disorders, 5) need for postoperative drain, 6) surgery lasting more than 1.5 hours, and 7) unwillingness to participate in the study.

\subsection{Induction and Intervention}

Laparoscopy was performed by a similar surgical team and an identical technique for all patients. It was used for general anesthesia in all patients using a combination of $2 \mu \mathrm{g} / \mathrm{kg}$ fentanyl, $1 \mathrm{mg}$ midazolam, $2 \mathrm{mg} / \mathrm{kg}$ propofol, and $0.5 \mathrm{mg} / \mathrm{kg}$ atracurium for induction. Furthermore, propofol infusion, fentanyl, and 50\% N2O/O2 mixture were used for maintenance anesthesia (Figure 1). In the control group, $250 \mathrm{mg}$ acetazolamide along with $20 \mathrm{ml}$ of water and paracetamol-like placebo solution (isotonic saline solution) were administered one hour before and after anesthesia, respectively. In the paracetamol group, acetazolamide-like placebo tablets (made by the laboratory of the School of Pharmacy, Mashhad University of Medical Sciences, Mashhad, Iran), and $20 \mathrm{ml}$ of water was administered one hour prior to anesthesia alongside the post-induction slow infusion of $1 \mathrm{~g}$ paracetamol, with $100 \mathrm{ml}$ isotonic saline solution over $15 \mathrm{~min}$. The group control received an acetazolamide-like placebo 1 hour and $20 \mathrm{ml}$ of water prior to 
anesthesia as well as the post-induction of a paracetamol-like placebo solution. A single dose of acetazolamide and paracetamol has no significant complications.

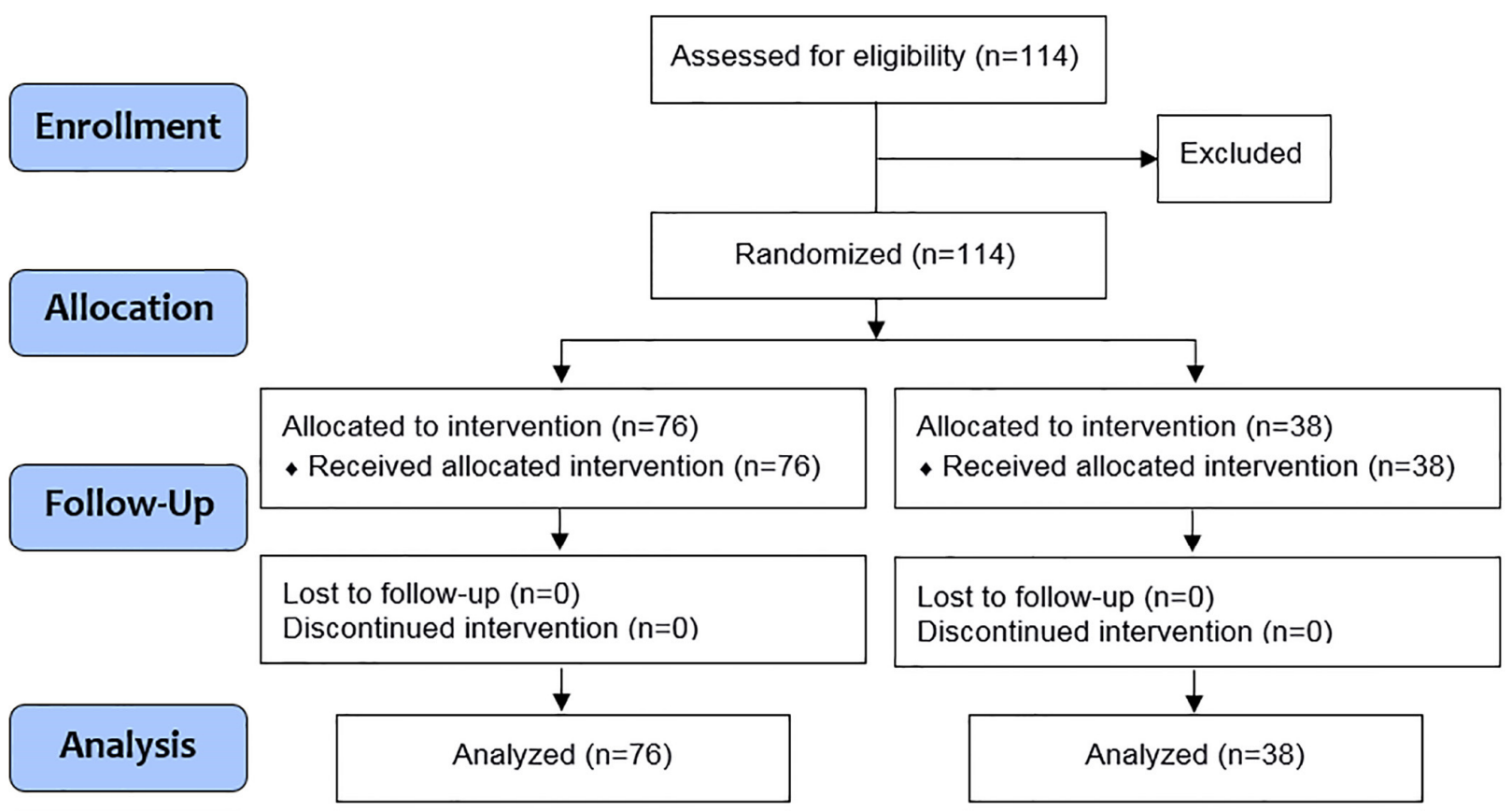

Figure 1. CONSORT flowchart of the study

\subsection{Outcome}

Patients' pain was evaluated using a numerical rating scale (NRS) in recovery, 24 hours after surgery, and before discharge. NRS is measured with a ruler and 0-10 score (11). Intravenous pethidine (25 mg q10 minute) was used during the recovery if NRS $\geq 4$. The patients were transferred from recovery room to ward after obtaining a pain scale score of less than 3 . The prescribed analgesic for all patients in the ward was $100 \mathrm{mg}$ diclofenac suppository administered every 8 hours. In the absence of pain control and NRS $\geq 4,50 \mathrm{mg}$ of pethidine was injected intravenously. An advisor blind to the study groups examined each of the patients for the location, occurrence, and severity of any kind of pain (i.e., incision site, diffuse abdominal, and shoulder pain) before and after the surgery (i.e., after waking up, at the time of recovery room discharge, the day after surgery, and upon hospital discharge) using NRS. Information such as age, gender, duration of surgery and recovery stay, and the amount of analgesics consumed in recovery and ward were recorded.

\subsection{Statistical analysis}

Statistical analysis was performed in SPSS, version 16 (SPSS Inc., Chicago, Illinois, USA). Kolmogorov-Smirnov test was run to determine the parametric and non-parametric data. Chi-square for trend test was utilized to analyze the nominal variables, and Fisher's exact test was used if needed. The comparison of the parametric data was performed by paired samples t-test, Wilcoxon signed-rank test, two-way repeated measure analysis of variance (ANOVA), and Mann-Whitney $U$ test. A p-value of $\geq 0.05$ was considered statistically significant. The anesthesiologist and pharmaceutical company prepared the placebo tablets and solutions. Paracetamol and placebo saline solution and the acetazolamide and placebo tablets were prepared separately by an individual who was not involved in the study results and evaluation. The patients, surgeon, and nurse who assessed the information were blinded of the study group. All the subjects underwent a laparoscopy under general anesthesia by a surgeon.

\subsection{Research ethics}

Ethical approval was obtained from the Ethics Committee of Mashhad University of Medical Sciences (Ref.: IR.MUMS.REC.1390.14). Written informed consent was obtained from the patients, and they were provided with sufficient instructions regarding the numerical rating system (NRS) and the expected locations of pain. The clinical trial was registered in the Iranian registry of clinical trials (IRCT) under registration number IRCT201206108384N2. 
http://www.ephysician.ir

\section{Results}

One hundred fourteen patients were included in the study, 98 (86\%) of whom were male. Demographic data including age, sex, weight, and duration of surgery are shown in Table 1. There was no statistically significant difference between groups of participants regarding these parameters.

Table 1. Patient demographic information Mean \pm Standard Deviation

\begin{tabular}{|l|l|l|l|l|}
\hline Demographic characteristics & Acetazolamide group & Paracetamol group & Placebo group & p-value \\
\hline age (years) & $40.5 \pm 12.5$ & $38.2 \pm 13.0$ & $36.4 \pm 12.5$ & 0.386 \\
\hline Sex (F/M) & $28 / 10$ & $26 / 12$ & $23 / 15$ & 0.561 \\
\hline Weight (Kg) & $77.5 \pm 19.6$ & $80.2 \pm 15.6$ & $76.2 \pm 16.2$ & 0.452 \\
\hline operation time (min) & $30.1 \pm 1.6$ & $28.7 \pm 6.7$ & $29.6 \pm 6.5$ & 0.639 \\
\hline
\end{tabular}

Table 2 summarizes the quantity and measurement of the most severe pain using NRS criteria for the incision site, abdominal, and shoulder pains in the three groups at the recovery room, first post-operative day, and hospital discharge.

Table 2. Patient pain severity based on NRS criteria

\begin{tabular}{|l|l|l|l|l|}
\hline Variable & Discharge from the hospital & 1st post-operative day & The recovery room \\
\hline Incisional Pain & Acetazolamide & $1.63 \pm 1.28$ & $3.66 \pm 2.0$ & $6.69 \pm 2.65$ \\
\cline { 2 - 5 } & Paracetamol & $0.6 \pm 0.45$ & $2.08 \pm 1.60$ & $4.03 \pm 2.75$ \\
\cline { 2 - 5 } & Placebo & $0.76 \pm 0.74$ & $2.63 \pm 1.91$ & $6.43 \pm 2.77$ \\
\cline { 2 - 5 } & p-value & 0.00 & 0.001 & 0.00 \\
\hline Abdominal pain & Acetazolamide & 0.00 & $0.47 \pm 0.13$ & $2.80 \pm 1.66$ \\
\cline { 2 - 5 } & Paracetamol & 0.00 & $0.59 \pm 0.39$ & $1.65 \pm 0.92$ \\
\cline { 2 - 5 } & Placebo & $0.23 \pm 0.05$ & $0.62 \pm 0.21$ & $2.18 \pm 1.42$ \\
\cline { 2 - 5 } & p-value & 0.133 & 0.121 & 0.352 \\
\hline Shoulder pain & Acetazolamide & 0.00 & 0.00 & $03 / 1 \pm 34 / 2$ \\
\cline { 2 - 5 } & Paracetamol & $0.37 \pm 0.16$ & $1.34 \pm 0.76$ & $3.00 \pm 1.74$ \\
\cline { 2 - 5 } & Placebo & $0.94 \pm 0.24$ & $1.48 \pm 0.84$ & $3.52 \pm 2.97$ \\
\cline { 2 - 5 } & p-value & 0.014 & 0.003 & 0.019 \\
\hline
\end{tabular}

Figure 2 illustrates the severity of postoperative pain in the three study groups after undergoing laparoscopic cholecystectomy. The referred shoulder pain (from abdominal and incisional pain) at the recovery room, the first day post-surgery, and upon hospital discharge was lower in the acetazolamide group than in the paracetamol group. On the other hand, the placebo group showed the highest frequency of referred shoulder pain. These differences were statistically significant among the three groups $(\mathrm{p}=0.03)$.

The mean severity of pain was higher in the incision site, compared to the subsequent diffuse abdominal and referred shoulder pains at all of the three assessed time points (i.e., the recovery room, the first post-operative day, and hospital discharge). The paracetamol group had lower incision site pain and diffuse abdominal pain than those treated with acetazolamide and placebo groups ( $\mathrm{p}=0.00$ and $\mathrm{p}=0.001$ respectively).

During the recovery, $69(60.5 \%)$ patients needed analgesics, 27 (71.0\%), $12(31.5 \%)$, and $30(78.9 \%)$ of whom were in groups acetazolamide, paracetamol, and placebo, respectively. Accordingly, the three groups showed a significant difference in terms of this variable $(\mathrm{p}=0.001)$. A direct pairwise comparison between the groups indicated no major difference between the acetazolamide and control groups $(\mathrm{p}=0.427)$. Nonetheless, the paracetamol group demonstrated a significantly lower need for analgesics compared to the control $(\mathrm{p}=0.001)$ and acetazolamide $(\mathrm{p}=0.001)$ groups.

A similar pattern was observed regarding the amount of the consumed analgesics during the recovery and within the first 24 hours of hospitalization $(\mathrm{p}=0.001)$. Figure 3 displays the comparison of the three groups in terms of the need for opioid analgesics. Pethidine consumption during recovery and within 24 hours in the paracetamol group was $57.1 \pm 13.2 \mathrm{mg}$ and $41.5 \pm 10.2 \mathrm{mg}$, in the acetazolamide group $88.2 \pm 11.3$ and $63.2 \pm 11.1 \mathrm{mg}$, and in the control group $91.3 \pm 12.5$ and $65.6 \pm 10.9 \mathrm{mg}$, respectively. The analgesic usage in the paracetamol group was lower in the other two groups in the recovery room and the first day ( $\mathrm{p}=0.032$ and $\mathrm{p}=0.021$ respectively). 


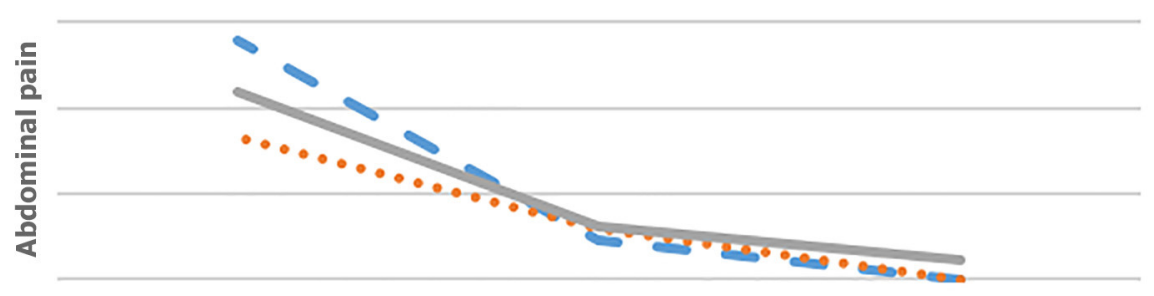

3

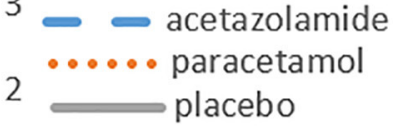

1

0

4
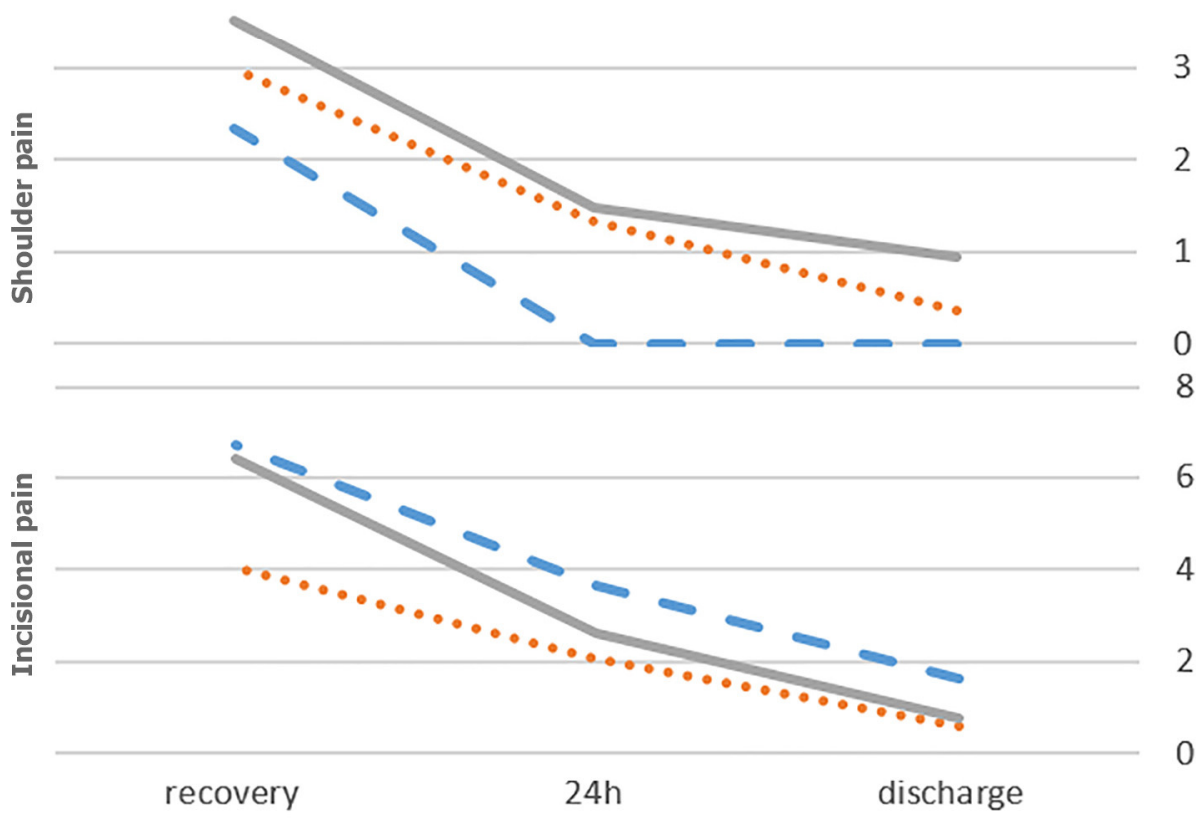

Figure 2. Pain severity [NRS score (0-10)] of abdominal, incisional and shoulder pain after laparoscopy in three study groups (acetazolamide group, paracetamol group, placebo group)

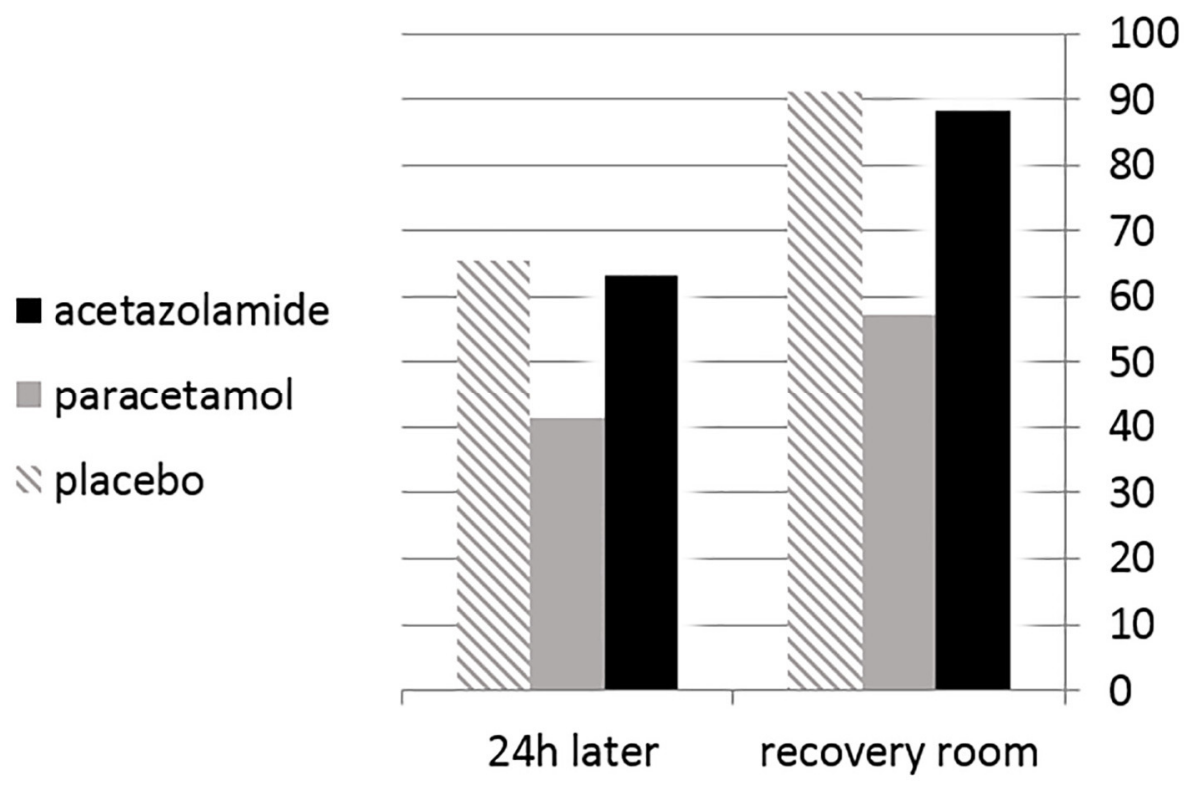

Figure 3. Need for analgesics among the three study groups 


\section{Discussion}

In the present study, we compared the analgesic effects of paracetamol and acetazolamide to determine the more effective agent in reducing post-laparoscopic pain. According to the results, the acetazolamide group had a lower frequency of referred shoulder pain in all three of the assessed time points (i.e., at the recovery room, the first postoperative day, and at the time of discharge), compared to the paracetamol group. Furthermore, the frequency of this pain was lower in the paracetamol group than in the placebo group. These differences were statistically significant among the three groups. The referred shoulder pain following the insufflation of carbon dioxide in laparoscopic surgery is due to tissue irritation by carbonic acid, which is formed out of the reaction of carbon dioxide with water; a process catalyzed by the CA.

Several possible mechanisms have been proposed for pain reduction by acetazolamide. Picker and Mac Nathan showed that the combination of acetazolamide and ion channel blockers was effective in reducing pain $(13,14)$. Acetazolamide can have both central and peripheral control on pain (9). This agent can cross the blood-brain barrier and affect the central nervous system (13). Moreover, this drug can elevate the pain threshold (15). Acetazolamide isoforms are often intracellular and only one type is found on the sarcolemma, which can account for the effectiveness of this medication in pain reduction. It is possible that tissue acidosis, an important side effect of acetazolamide, be responsible for the higher frequency of diffuse abdominal pain and referred shoulder pain in group A in the recovery room. Bala et al. (2015) observed that visceral pain scores were significantly lower while resting, coughing, and moving at $2,4,6,12$, and 4 hours postoperatively (16). The effect of a single dose of acetazolamide is known to last for 4-6 hours. The duration of pain relief in the mentioned study as well as in a study by Harvey et al. (17) was only limited to this period.

The results of the current study revealed that the administration of paracetamol as an analgesic reduced the incision site pain, diffuse abdominal pain, and the amount of needed analgesics in the recovery room and the first 24 hours later. However, the acetazolamide group did not show any significant difference from the paracetamol group regarding the amount of analgesics used on the first post-operative day. In a study conducted in Saudi Arabia, the administration of paracetamol in a dose of $1 \mathrm{~g}$ three times a day indicated no significant reduction in postlaparoscopic cholecystectomy pain (18). In our study, the paracetamol group experienced pain in a significantly lower frequency compared to the other two groups in the recovery room. Nevertheless, this difference disappeared between the paracetamol and acetazolamide groups throughout the first day of hospital stay. Furthermore, acetazolamide reduces serum $\mathrm{pH}$ and increases renal bicarbonate excretion, which may lead to enhanced peritoneal acidification (19). However, in this study, group P had a lower need for analgesics on the first post-operative day, compared to the other groups due to receiving just one dose of acetazolamide. In line with our study, MoazeniBistgani reported that although acetazolamide can reduce referred pain to the right shoulder by reducing the acidity of the peritoneal irrigation fluid, it can also increase abdominal pain in the damaged surgery site tissues by producing tissue acidosis (as a side effect of the drug) (20). In a study in India, the administration of acetazolamide reduced the shoulder pain and the overall score of pain in the patients undergoing laparoscopic nephrectomy (21). In our study, shoulder pain was significantly less frequent in the acetazolamide group than the other two. The frequencies of incision site pain and diffuse abdominal pain were lower in the paracetamol group, compared to those in the other groups. Singh reported different results. However, this discrepancy can be attributed to the differences in the administered drug doses since we used a mere $250 \mathrm{mg}$ acetazolamide dosage whereas Singh administered 5 $\mathrm{mg} / \mathrm{kg}$. Additionally, in Singh's study, the patients received acetazolamide immediately after anesthesia through a nasogastric tube, while in our study, the drug was administered $1 \mathrm{~h}$ before anesthesia.

\section{Study limitations}

The major limitation of our study was the non-assessment of serum and other body fluid $\mathrm{pH}$, before and after acetazolamide administration. Therefore, it was not possible to determine the definite reason for the higher frequency of diffuse abdominal and incision site pains.

\section{Conclusions}

The results of this study demonstrated that acetazolamide could reduce shoulder pain in patients undergoing laparoscopic cholecystectomy, but it was not effective for other pains using the given amount of paracetamol. On the other hand, we clinically recommend that intra-operative administration of paracetamol is just significantly helpful in reducing incisional and abdominal pain, and there may be a need for future studies with further doses of paracetamol. 


\section{Acknowledgments:}

This study was supported by Research Vice-chancellor, Mashhad University of Medical Sciences (Ref: 900337) and we would like to thank the Foundation of Martyrs and Veterans of Khorasan Razavi Province (Iran) for their cooperation in this study.

\section{Conflict of Interest:}

There is no conflict of interest to be declared.

Authors' contributions:

All authors contributed to this project and article equally. All authors read and approved the final manuscript.

\section{References:}

1) Yeh CN, Tsai CY, Cheng CT, Wang SY, Liu YY, Chiang KC, et al. Pain relief from combined wound and intraperitoneal local anesthesia for patients who undergo laparoscopic cholecystectomy. BMC surgery. 2014;14:28. doi: 10.1186/1471-2482-14-28, PMid: 24886449, PMCid: PMC4026815

2) Asiedu MN, Mejia GL, Hubner CA, Kaila K, Price TJ. Inhibition of carbonic anhydrase augments GABAA receptor-mediated analgesia via a spinal mechanism of action. The journalof pain: official journal of the American Pain Society. 2014 Apr;15(4):395-406. doi: 10.1016/j.jpain.2014.01.001, PMid: 24412803, PMCid: PMC3972347

3) Donnini I, Nannumli S, Valenti R, Pescini F, Bianchi S, Inzitari D, et al. Acetazolamide for the prophylaxis of migraine in CADASIL: a preliminary experience. The journalof headache and pain. 2012 Jun;13(4):299302. doi: 10.1007/s10194-012-0426-9, PMid: 22367627, PMCid: PMC3356473

4) Lyall DA. Unexpected control of a patient's refractory epilepsy when treating glaucoma with acetazolamide. Canadian journal of ophthalmology Journal canadien d'ophtalmologie. 2008 Jun;43(3):377. doi: 10.3129/i08-036, PMid: 18443620

5) Haji-Rahim-Khan S. Iran Farma (Textbook of Iran official drugs). 1st ed. Tahran: Teimor Zade 2006. 6078.

6) Brunton L, Lazo J, Parker K, Goodman Gilman A. Renin and angiotensin. Goodman \& Gilman's The Pharmacological Basis of Therapeutics. 2006;11: 789-821.

7) Rodríguez-Navarro AJ, Berde CB, Wiedmaier G, Mercado A, Garcia C, Iglesias V, et al. Comparison of neosaxitoxin versus bupivacaine via port infiltration for postoperative analgesia following laparoscopic cholecystectomy: A randomized, double-blind trial. Regional anesthesia and pain medicine. 2011 Mar 1; 36(2):103-9. doi: 10.1097/AAP.0b013e3182030662, PMid: 21425506

8) Aghamohammadi H KM, Gharaei B. Acetazolamide effect on postoperative pain after Laparoscopic Surgery. J Army Univ Med Sci I R Iran. 2009;7(2):95-8.

9) Issberner U, Reeh PW, Steen KH. Pain due to tissue acidosis: a mechanism for inflammatory and ischemic myalgia? Neuroscience letters. 1996 Apr 26;208(3):191-4. doi: 10.1016/0304-3940(96)12576-3

10) Schwarz MG, Namer B, Reeh PW, Fischer MJ. TRPA1 and TRPV1 Antagonists Do Not Inhibit Human Acidosis-Induced Pain. The Journal of Pain. 2017 May 31; 18(5):526-34. doi: 10.1016/j.jpain.2016.12.011, PMid: 28062311

11) Young IA1, Cleland JA, Michener LA, Brown C.Reliability, construct validity, and responsiveness of the neck disability index, patient-specific functional scale, and numeric pain rating scale in patients with cervical radiculopathy. Am J Phys Med Rehabil. 2010 Oct;89(10):831-9. doi: 10.1097/PHM.0b013e3181ec98e6, PMid: 20657263

12) Phelps P1, Cakmakkaya OS, Apfel CC, Radke OC. A simple clinical maneuver to reduce laparoscopyinduced shoulder pain: a randomized controlled trial. Obstet Gynecol. 2008 May;111(5):1155-60. doi: 10.1097/AOG.0b013e31816e34b4, PMid: 18448749

13) Pickkers P, Hughes AD, Russel FG, Thien T, Smits P. In vivo evidence for KCa channel opening properties of acetazolamide in the human vasculature. British journal of pharmacology. 2001;132(2):44350. doi: 10.1038/sj.bjp.0703825, PMid: 11159693, PMCid: PMC1572572

14) McNaughton $\mathrm{NC}$, Davies $\mathrm{CH}$, Randall A. Inhibition of alpha $(1 \mathrm{E}) \mathrm{Ca}(2+)$ channels by carbonic anhydrase inhibitors. Journal of pharmacological sciences. 2004 Jun;95(2):240-7. doi: 10.1254/jphs.FP0040032, PMid: 15215649

15) Woehlck HJ, Otterson M, Yun H, Connolly LA, Eastwood D, Colpaert K. Acetazolamide reduces referred postoperative pain after laparoscopic surgery with carbon dioxide insufflation. Anesthesiology. 2003 Oct;99(4):924-8. doi: 10.1097/00000542-200310000-00027, PMid: 14508327 
16) Hummel M, Knappenberger T, Reilly M, Whiteside GT. Pharmacological evaluation of NSAID-induced gastropathy as a" Translatable" model of referred visceral hypersensitivity. World Journal of Gastroenterology. 2017 Sep 7; 23(33):6065. doi: 10.3748/wjg.v23.i33.6065, PMid: 28970722, PMCid: PMC5597498

17) Bala I, Bhatia N, Mishra P, Verma GR, Kaman L. Comparison of preoperative oral acetazolamide and intraperitoneal normal saline irrigation for reduction of postoperative pain after laparoscopic cholecystectomy. Journal of Laparoendoscopic \& Advanced Surgical Techniques. 2015 Apr 1; 25(4):28590. doi: 10.1089/lap.2014.0507, PMid: 25768238

18) Harvey JW, Offlerson M, Yun H, Connolly LA, Eastwood D, Colpaert K. Acetazolamide reduces postoperative pain after laparoscopic surgery with CO2 insufflation. Anesthesiology 2003;99: 924-8, doi: 10.1097/00000542-200310000-00027, PMid: 14508327

19) Radhakrishnan R, Sluka KA. Acetazolamide, a carbonic anhydrase inhibitor, reverses inflammationinduced thermal hyperalgesia in rats. Journal of Pharmacology and Experimental Therapeutics. 2005;313(2):921-7. doi: 10.1124/jpet.104.082776, PMid: 15743922

20) Abdulla S, Eckhardt R, Netter U, Abdulla W. A randomized, double-blind, controlled trial on non-opioid analgesics and opioidconsumption for postoperative pain relief after laparoscopic cholecystectomy. Acta anaesthesiologica Belgica. 2012;63(1):43-50.

21) Moazeni-Bistgani M, Mohammad Ali-Beigi F, Shahrjerdi S. Assessment of oral acetazolamide on postoperative pain after laparoscopic cholecystectomy. J Shahrekord Univ Med Sci . 2010; 12(2): 21-6

22) Singh R, Sen I, Wig J, Minz M, Sharma A, Bala I. An acetazolamide based multimodal analgesic approach versus conventional pain management in patients undergoing laparoscopic living donor nephrectomy. Indian journal of anaesthesia. 2009 Aug; 53(4):434. 